\title{
La asistencia sanitaria a obreros heridos: el hospital Sanatorio Adaro de Langreo
}

\author{
María Zapico López* \\ Universidad de Nantes
}

\section{RESUMEN}

En el presente artículo se realiza un análisis arquitectónico de uno de los hospitales de empresa más reseñables de Asturias surgido a principios del siglo XX: el Sanatorio Adaro. Radicado en Langreo, fue levantado por iniciativa de la Sociedad Metalúrgica Duro Felguera, la principal empresa minero-siderúrgica de la zona, para disfrute de sus empleados en caso de accidente o enfermedad laboral. Además, a modo de introducción, el trabajo revisa las fórmulas de solidaridad colectiva adoptadas para proporcionar cobertura sanitaria a los trabajadores heridos a partir del siglo XIX y durante los primeros años de la centuria siguiente. Del mismo modo, se hace un repaso de las tácticas de participación patronal en los dispositivos asistenciales para obreros, tanto como iniciativa paternalista como dentro de las obligaciones dispuestas en la legislación al respecto.

\section{PALABRAS CLAVE:}

Hospital de empresa, paternalismo industrial, sociedades de socorros mutuos, Sociedad Metalúrgica Duro Felguera, Langreo.

\section{ABSTRACT}

This paper provides an architectural analysis of one of the most significant company early twentieth century hospitals of Asturias: the Sanatorio Adaro. This hospital, located in Langreo was built by initiative of the Sociedad Metalúrgica Duro Felguera, the leading mining and steel company of the area, for the enjoyment of its employees if an accident or a work related disease took place. Moreover, by way of introduction, the article checks the collective solidarity formulations taken to provide health coverage to injured workers on the nineteenth century and the early years of the following century. In the same way, a review of employers tactics participating in the assistive devices for workers is made, as well as paternalistic initiative within the obligations stipulated in the legislation.

\section{KEY WORDS:}

Company hospital, industrial paternalism, friendly societies, Sociedad Metalúrgica Duro Felguera, Langreo.

* Beneficiaria del Programa Clarín -Marie Courie- Cofund de Ayudas Postdoctorales del Principado de Asturias, en el CRHIA (Centre de Recherches en Histoire Internationale et Atlantique), Universidad de Nantes. 
Introducción

El tema de la dotación de recursos asistenciales para trabajadores ha sido abordado en las últimas décadas por investigadores provenientes de diferentes ámbitos académicos. El trabajo que aquí se presenta pretende ser una nueva aportación a esta temática a través del estudio de la trayectoria constructiva del hospital para obreros Sanatorio Adaro de Langreo, uno de los mejor dotados de toda Asturias, surgido en el contexto de la Revolución Industrial. Mediante un exhaustivo estudio, se van ilustrando las diferentes etapas evolutivas de este establecimiento hospitalario, levantado a principios del siglo XX, como un ejemplo que encarna las intenciones $\mathrm{y}$ propósitos que llevaron a las empresas a promocionar este tipo de servicios destinados a obreros, en un contexto de políticas paternalistas, cambios sociales y legislación formulada al respecto. La principal aportación del trabajo es mostrar el resultado de la reflexión de un extenso estudio de material documental, fotográfico y hemerográfico inédito, hasta entonces no estudiado ni publicado. Con todo, el objetivo final y pretensión esencial ha sido contribuir a la puesta en valor y conservación del legado patrimonial como exponente de nuestra memoria colectiva, para trasmitirlo a generaciones futuras, ya que solamente a partir del conocimiento y difusión se puede asegurar su preservación.

La irrupción de la Revolución Industrial no sólo provocó incidencias en el plano económico y tecnológico, también acarreó una profunda convulsión visible a través de una nueva dinámica del trabajo a la cual tuvo que habituarse la naciente clase obrera. En este sentido, la mecanización, unida a las penosas condiciones de salubridad de los centros de trabajo, trajo como consecuencia un rápido crecimiento de los accidentes y las enfermedades laborales.

En medio de tales mutaciones, el surgimiento, crecimiento y rápida consolidación como clase del proletariado propició que, la atención sanitaria hacia el obrero accidentado en su lugar de trabajo, totalmente desprotegido y necesitado de tutela, se convirtiese en una de sus principales denuncias. Del mismo modo, comenzaron a ser persistentes las quejas referidas a la falta de seguridad del centro laboral o la situación del obrero accidentado, inválido, o de su familia en caso de fallecimiento, abocados a la marginalidad y beneficencia.

En lo que se refiere a la España decimonónica, dentro de un contexto en el que las fórmulas de organización corporativa vigentes durante el
Antiguo Régimen se habían diluido, la filosofía escasamente intervencionista del nuevo sistema liberal unida al desarraigo social traído por el trasvase de trabajadores del campo a la ciudad, aumentó la vulnerabilidad de los obreros y sus familias.

No obstante, constituirá un hecho de notable importancia la regulación del fenómeno asociativo, aunque de manera un tanto restrictiva, a través de La Real Orden de 28 de febrero de $1839^{1}$. En ella, la Regente María Cristina autorizaba la constitución de asociaciones bajo la modalidad de las sociedades de socorros mutuos. En este sentido, afloraron trabajadores encargados de agruparse, con mayor o menor fortuna, con la finalidad de asegurarse una cobertura asistencial a través de redes de solidaridad colectiva y el fenómeno mutualista, dando lugar a asociaciones de socorros mutuos. Este hecho les proporcionaba el acceso a asistencia médica y farmacéutica mediante una fórmula de financiación a través de las cuotas que periódicamente abonaban los propios obreros ${ }^{2}$; en ocasiones se distribuía una cuantía económica a la familia del trabajador mientras este se encontraba imposibilitado.

Habrá que esperar hasta finales de la década de 1880 para encontrar una ley en este sentido. A este respecto, fue clave la promulgación, de la mano de Mateo Sagasta, de la Ley de Asociaciones el 30 de junio de $1887^{3}$, publicada en la Gaceta doce días después. Se trataba de la primera ley española sobre derecho de asociación. Reconocía, en su artículo primero, el libre derecho de libre ejercicio a asociaciones para fines religiosos, políticos, científicos, artísticos, benéficos y de recreo o cualquier otro que no persiguiera como fin único y exclusivo el lucro o la ganancia. Igualmente quedaron en ella incluidos de manera explícita los

\footnotetext{
1 "Real Orden de 28 de febrero de 1839: Autorización y fomento de las sociedades de socorros mutuos", en MARTÍN VALVERDE, Antonio, La legislación social en la historia de España. De la Revolución liberal a 1936, Madrid, 1987, pp.8-9.

2 VILAR RODRÍGUEZ, Margarita y PONS PONS, Jerònia, “El papel de las sociedades de socorro mutuo en la cobertura del riesgo de enfermedad en España (1870-1942)”, ponencia presentada en el X Congreso Internacional de la AEHE, Septiembre 2011, Universidad Pablo de Olavide Carmona (Sevilla), en línea, consultado el 17 de septiembre de 2015. URL: http://www.aehe.net/xcongreso/pdf/sesiones/seguros/el\%20papel\%20de\%20las\%20sociedades\%20de\%20socorro\%20mutuo\%20en\%20la\%20cobertura\%20de\%20riestgo.pdf

3 La Ley de Asociaciones puede ser consultada en Colección legislativa de España, vol. CXXXVIII, pp.677-683.
} 


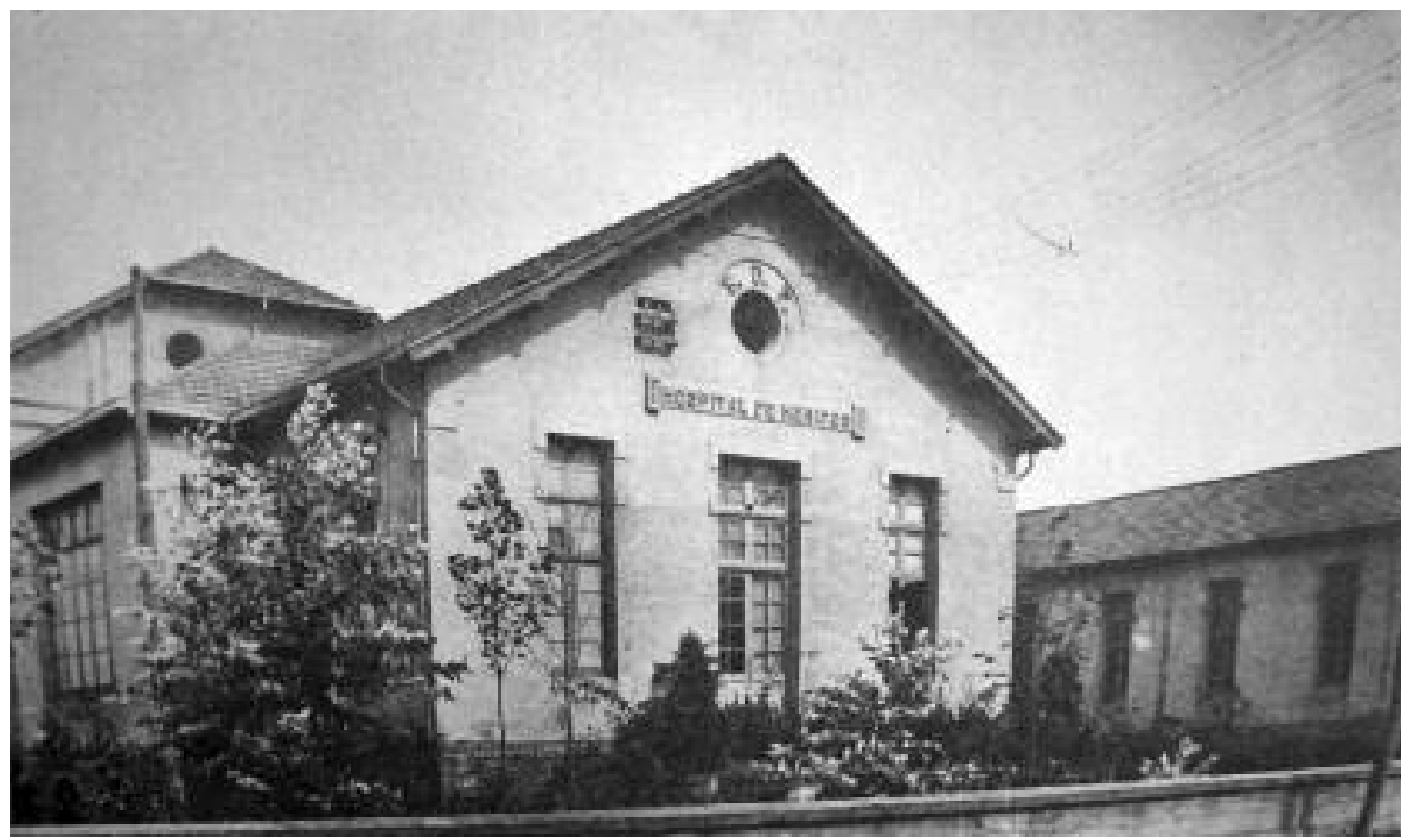

Fig. 1. Vista exterior del primitivo Hospital de Heridos de la Sociedad Metalúrgica Duro Felguera. Fuente: Archivo Grupo Duro Felguera

socorros mutuos, las sociedades de previsión y las cooperativas de producción de crédito o de consumo ${ }^{4}$.

En otro orden de cosas, también encontramos la fórmula en la que la patronal se hizo cargo de la tutela y gestión de cajas de socorros mutuos ${ }^{5}$, dentro de los postulados coercitivos del paternalismo industrial mediante una estrategia de domesticadora, en absoluto inocente. Los directivos ofrecieron programas de cobertura sanitaria con el objetivo de frenar las crecientes huelgas y fueron incorporando recursos asistenciales en espacios productivos. Este repentino interés por la mejora de la salud del obrero se explicaba como una estrategia que desembocaría en el trabajo productivo. Los empresarios comenzaron a enmascarar estas intenciones, como si se trata-

4 MAZA ZORRILLA, Elena, "Las clases populares en España: continuidad y transformaciones en su perfil asociativo 1887-1930)", Investigaciones históricas: Época moderna y contemporánea, $\mathrm{n}^{\circ} 15$, Servicio de publicaciones de la Universidad de Valladolid, Valladolid, 1995, pp.297314.

5 La presencia de control patronal se veía sobre todo en las inspección de las labores realizadas en este tipo de asociaciones mediante unos socios protectores que solían se parte de la patronal, y en ellas solían premiarse la fidelidad de los obreros. URÍA GONZÁLEZ, Jorge, "Mutualismo y sociedades de socorros mutuos en Asturias. Una visión de conjunto (1898-1936)", en CASTILLO, Santiago (Ed.), Solidaridad desde abajo. Trabajadores y Socorros Mutuos en la España Contemporánea, Centro de Estudios Históricos, UGT, Madrid, 1995, pp. 225-244. ra de pequeñas concesiones, para acallar el descontento de los obreros. ${ }^{6}$

De otro lado, encontramos los preceptos legislativos relacionados con la cobertura sanitaria y la creación de espacios asistenciales por parte de los patronos. Para el caso que nos ocupa, cobra especial importancia el proyecto de ley presentado por ministro de Gobernación, Eduardo Dato, en noviembre de 1899, que desembocó en la promulgación de la Ley de Accidentes de Trabajo de 30 de enero de $1900^{7}$. En concreto, en su artículo segundo, se responsabilizaba al patrono de los accidentes ocurridos a sus operarios

6 Sus tácticas basaron su sustento en la extrapolación de las relaciones paterno-filiales a otro tipo de relaciones sociales, la del patrón y el obrero. Con tales premisas, se pretendió separar al obrero de su vida anterior en todos los aspectos y conseguir que únicamente dependiese de su salario. Se trataba, por tanto, de una disciplina de docilidad, de modelado, de regeneración de hábitos y costumbres. La base ideológica del paternalismo partía de la premisa de que la irrupción de la industrialización distorsionaba un orden existente hasta el momento en las relaciones sociales y creaba un nuevo tipo de trabajador inexistente hasta entonces, el obrero. La nueva clase proletaria no se adaptaba al rendimiento laboral exigido, por lo que era necesario crear un hombre nuevo modelado acorde con los postulados marcados por ingenieros y empresarios. SIERRA ÁLVAREZ, José, “De las utopías socialistas a las utopías patronales: para una genealogía de las disciplinas industriales paternalistas”, Revista Española de Investigaciones Sociológicas, Madrid, 1984, pp.29-44.

$7 \quad$ La Gaceta de 31 de enero de 1900. 
con motivo y en el ejercicio de la profesión o trabajo que realizasen. Además, en su artículo cuarto, estipulaba cómo el patrono se hallaba igualmente obligado a facilitar la asistencia médica y farmacéutica al obrero hasta que se hallase en condiciones de volver al trabajo.

Como es lógico, las prácticas de cobertura industrial echaron raíces en las principales zonas industriales del país. Dentro del marco geográfico del Principado de Asturias, Langreo se erigió como uno de los enclaves en el que la industrialización se dejó sentir de modo más intenso. En este municipio, fue la sociedad Duro y $\mathrm{Cía}^{8}$, una de las más prósperas, la que sobresalió por una fuerte política paternalista que incluía la construcción de escuelas, economatos, centros hospitalarios y algunas viviendas $^{9}$. Fue, además, la encargada de gestionar una de las primeras cajas de socorros de las que se tiene constancia en el municipio, con el reglamento de julio de 1867 para los trabajadores de dicha empresa y también para los de la Fábrica de Vega de Gil y Compañía ${ }^{10}$. Estaba dirigida y administrada por una Junta que decretaba los socorros

8 La sociedad colectiva Duro y Cía se constituyó el 22 de febrero de 1858, ante el notario José de Celis Ruiz, en Madrid. Comenzó siendo una fábrica siderúrgica concebida por el riojano Pedro Duro Benito radicada en Vega de Turiellos (La Felguera-Langreo). En los inicios del siglo XX, la compañía colectiva Duro y Cía emprendió una gran transformación que supuso su conversión en sociedad anónima, dando lugar a la Sociedad Metalúrgica Duro Felguera (S.M.D.F.), en el año 1900. El cambio facilitó la entrada de nuevos capitales y con ello una variación de estrategia empresarial de la Sociedad que pasaría por ser la de convertirse en una gran sociedad minero-siderúrgica en el ámbito nacional. Con posterioridad, Duro Felguera comenzó su dedicación a la producción de bienes de equipo, para ir diversificando paulatinamente sus negocios. En los años centrales de la década de 1980 la empresa experimentó un cambio en su trayectoria con la finalidad de adaptarse a la demanda del mercado y comienza a centrarse en la ejecución de proyectos para el sector energético. ANES ÁLVAREZ, Rafael, "Los Capitanes de Industria”, en VÁZQUEZ, Juan Antonio y OJEDA, Germán (coord.)., Historia de la economía asturiana, Editorial Prensa Asturiana, Oviedo, 1994, pp.305-320, OJEDA, Germán, Duro Felguera. Historia de una gran empresa industrial, Grupo Duro Felguera S.A., Oviedo, 2000. p.33.

9 Sobre la vivienda obrera de la Sociedad Metalúrgica Duro Felguera véase: ZAPICO LÓPEZ, María,"La vivienda obrera de Duro Felguera. Un ejemplo de habitación obrera del siglo XX: el barrio Marqués de Urquijo de La Felguera”, en ÁLVAREZ ARECES, Miguel Ángel (Ed.), Patrimonio Industrial y paisaje, CICEES, Gijón, 2010, pp. 559-567. y ZAPICO LÓPEZ, María, "El barrio de La Nalona: un proyecto de poblado obrero desaparecido de Langreo" en ÁLVAREZ ARECES, Miguel Ángel (Ed.), Patrimonio inmaterial e intangible de la industria artefactos, objetos, saberes y memoria de la industria, CICEES, Gijón, 2012, pp.391-398.

10 Para que los obreros tuvieran derecho a socorro era indispensable haber sufrido el descuento de la aportación que debían concederse. Dicha junta estaba compuesta por el administrador de las fábricas, el director y subdirector de la fábrica, el tenedor de libros, el capellán, el médico y tres operarios elegidos por sus compañeros y renovados cada dos años. El cometido de esta caja de socorros mutuos era el de amparar a proletarios y empleados en el caso de que se hallasen imposibilitados para trabajar por enfermedad o accidente. Tal es así que se cubría la asistencia médica a ellos y sus familias, aportando medicamentos e ingreso hospitalario para los casos más graves. Asimismo se contemplaba el socorro monetario mientras estuviesen impedidos para realizar su trabajo y una pequeña indemnización para aquellos que quedasen incapacitados de por vida. Junto a esto, la empresa se comprometió a contratar para sus instalaciones un médico cirujano así como la instalación del pertinente establecimiento hospitalario para los obreros heridos de mayor gravedad. Se estableció, asimismo, un pequeño recinto hospitalario para aquellos heridos de mayor gravedad.

Para sufragar esta caja de socorros se efectuaba un descuento forzoso a los trabajadores, el cual oscilaba entre el uno y el dos por ciento sobre sus haberes, en proporción al riesgo de accidente que corrían en su sección laboral. Por otro lado, iban a parar a sus arcas el dinero recolectado de las multas impuestas a los operarios indisciplinados, donativos de particulares o subvenciones que se concediesen a la Sociedad. Del mismo modo, la fábrica concedía una subvención de 2000 reales anuales con destino a dicha caja.

Con posterioridad, y como consecuencia de la Ley de Accidentes de Trabajo de 30 de enero de 1900, Duro y Cía, en ese momento constituida como Sociedad Metalúrgica Duro Felguera, se contempló la opción de levantar uno de los hospitales de empresa mejor dotados de toda Asturias, al igual que habian hecho otras empresas de la provincia en los años iniciales del siglo $\mathrm{XX}^{11}$.

estipulada durante tres meses consecutivos. "Reglamento para la Caja de Socorros de las fábricas de hierro de La Felguera y de Vega establecidas en el valle de Langreo”, en DURO BENITO, Pedro, Altos hornos y fábrica de hierros de la Sociedad Metalúrgica de Duro y Cía. Contestación al interrogatorio hecho por la Comisión de información Parlamentaria acerca del estado de las clases obreras, Imp. y Lit. de Brid y Regadera, Oviedo, 1871, pp. 30-38.

11 MENÉNDEZ NAVARRO, Alfredo, "Hospitales de empresa: los primeros pasos de la medicina del trabajo", en VV.AA., Trabajo y salud: desde la protección a la prevención, catálogo de exposición, Instituto Nacional de Seguridad e Higiene en el Trabajo, Fundación Francisco Largo Caballero, Mutua Fraternidad-Muprespa, Madrid, 2010, pp. 328-345. 


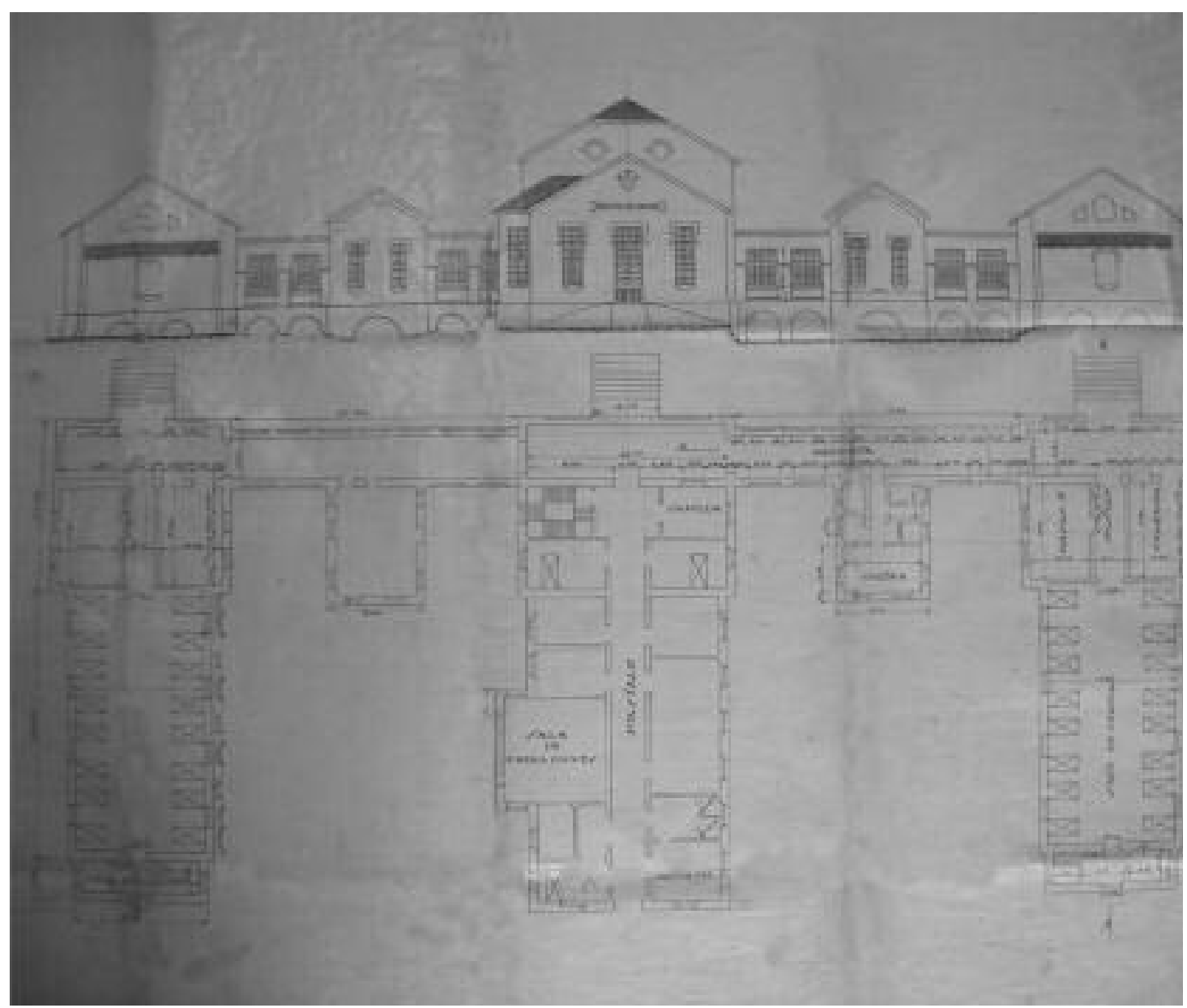

Fig. 2. Proyecto de ampliación del Hospital de Heridos, 1929. Fuente: Archivo histórico de HUNOSA Pozo Fondón

\section{Análisis histórico y constructivo del hospital Sanatorio Adaro}

El principal recinto hospitalario relacionado con los accidentes laborales de Langreo fue el Hospital de Heridos promocionado por la Sociedad Metalúrgica Duro Felguera. Radicado en Sama ${ }^{12}$, se trata de un hospital de empresa concebido en el contexto de la Ley de Accidentes de Trabajo de 1900 y gracias a las reivindicaciones de diferentes asociaciones obreras del concejo.

Como antecedentes que desencadenan su definitiva concepción apuntaremos la aparición, desde inicios del siglo XX en los Libros de Ac-

12 En este sentido, encontramos otros hospitales levantados en Asturias en los primeros años del siglo XX, como el Sanatorio de Bustiello erigido por la Sociedad Hullera Española o el de Solvay, en las minas de Lieres. DIRECCIÓN GENERAL DE AGRICULTURA, MINAS Y MONTES, Informe relativo al estado económico y situación de los obreros de las Minas y Fábricas metalúrgicas de España y organismos de protección instituidos en beneficio de los mismos, Madrid, Est.Tip.de El Liberal,1911, pp.31-33. tas del Ayuntamiento de Langreo, de instancias provenientes de asociaciones obreras subrayando la necesidad de acometer un complejo hospitalario en el concejo. Las peticiones fueron in crescendo en paralelo al crecimiento de la industria en este enclave, el cual había traído consigo un aumento de afectados por accidentes laborales los cuales eran trasladados a Oviedo y Gijón.

Hasta entonces existían algunos hospitalillos de pequeñas dimensiones o casas de socorro, a todas luces insuficientes para albergar a una población que había duplicado su porcentaje en pocos años. Pese a todo, el Ayuntamiento no podía hacer frente a una obra de tal magnitud, en parte porque no contaba con capital suficiente, y porque, además, legalmente, en ese momento no estaba permitido construir un hospital en el municipio por la poca distancia existente con el de la capital ${ }^{13}$. Con estos argumentos, el nue-

13 ZAPICO LÓPEZ, María, Arqueología industrial urbana. Arquitectura industrial y patrimonio social en Langreo, Tesis Doctoral Inédita. Universidad de Oviedo, 2014, p. 578 y ss. 
vo hospital solo podría llevarse a cabo a iniciativa particular, motivo por el que la Presidencia de las Consistoriales, mediante diversas gestiones, intentó alentar a las empresas locales para que lo costeasen ${ }^{14}$.

Desde 1904, Luis Adaro y Magro, vocal del consejo de Administración de Duro Felguera, mostró su favorable disposición a que esta Sociedad gestionase la erección de un hospital. Sin embargo, Antonio Velázquez Duro, también vocal de la misma empresa, no acogió la idea con demasiado entusiasmo, resultándole innecesario este servicio por contar la empresa con otro tipo de instalaciones sanitarias. Como consecuencia, la propuesta se dejó en suspenso, aunque las presiones por parte de los obreros se seguirán sucediendo.

No fue hasta 1906 cuando encontramos una proposición firme para promover un hospital por parte de la S.M.D.F ${ }^{15}$. Desde aquel entonces la controversia vino por la disputa, entre el Ayuntamiento y Duro, en torno a la elección de los terrenos para su emplazamiento. De una parte, el propósito de las Consistoriales era el de adquirir unos terrenos sitos en La Felguera, inmediatos a la plaza del mercado, propiedad de aquella Sociedad $^{16}$. Para obtenerlos, pretendía materializar una operación consistente en la permuta de los mismos por otros terrenos ${ }^{17}$ en Sama, cerca del parque de esta localidad, y que contemplaban como los más apropiados para albergar el futuro hospital. En esta ocasión, el inconveniente se encontraba en que la superficie del futuro hospital el cual sobrepasaba el umbral de dicha parcela, haciéndose necesario trasladar el lavadero adyacente al parque ${ }^{18}$. Ante la complejidad de esta operación, finalmente las Consistoriales deciden

14 Desde el inicio el Ayuntamiento de Langreo se mostró en desacuerdo ante la idea de la creación de un hospital con todas sus dependencias, personal y efectos, opinando que daría resultados similares la implantación de una casa de socorros con buenas instalaciones y servicio de guardia. Libros de Actas de Sesiones del Ayuntamiento. Tomo 241904. Folio 4 vuelto. Archivo Municipal del Ayuntamiento de Langreo.

15 Esta situación favorable se produce coincidiendo con el ascenso de Luis Adaro y Magro al puesto de Director general de Consejo de Administración de Duro Felguera en ese año 1906 tras la integración de la Unión Hullera.

16 Libro de Actas de la Comisión Delegada, 11 de abril de 1906. Archivo Histórico Grupo Duro Felguera.

17 Se estima como conveniente este lugar de emplazamiento por tratarse de un lugar rodeado de toda clase de vías de comunicación y rodeado de jardines. Ibídem, 24 abril de 1906.

18 Libros de Actas de Sesiones del Ayuntamiento. Tomo 1906II. Folio 21. Archivo Municipal del Ayuntamiento de Langreo. efectuar una permuta por otro solar, que adquiriría a precio económico, sito entre las líneas ferroviarias de Samuño y Santa Ana ${ }^{19}$. Este es el lugar en el que definitivamente se localizó el conjunto hospitalario, denominado en su origen como Hospital de Heridos.

Debido a las dimensiones del proyecto, su ejecución no se realizó en toda su extensión inicialmente, procediéndose a su construcción por pabellones ${ }^{20}$. En abril de 1907 se preveía comenzar las obras en el plazo más breve posible, no excediéndose su duración más de un año. $\mathrm{Al}$ propio tiempo, se remitieron lo planos y la memoria, junto con el presupuesto ${ }^{21}$.

No obstante, habrá que esperar hasta 1909 para que se concrete el acuerdo de construcción definitiva gracias a la iniciativa de Luis Adaro y Magro. Pese a todo, la campaña si dilató en el tiempo, avanzándose a medida que se iban aprobando distintas partidas presupuestarias hasta que el edificio fue inaugurado oficialmente el $12 \mathrm{fe}-$ brero de $1914^{22}$.

En lo que respecta a su emplazamiento, el terreno escogido, rodeado por una cerca de hormigón armado, a septentrión lindaba con un camino paralelo al río Nalón; al sur, con el solar ocupado por la sociedad de socorros mutuos de la propia empresa; a oriente, con el ramal de Samuño del Ferrocarril de Langreo mientras que, al oeste, lo delimitaba el ferrocarril de vía estrecha de la Sociedad.

De la primera fase constructiva del edificio no se ha podido localizar el proyecto, aunque quizás su autoría se deba a Manuel del Busto ${ }^{23}$. A través de la documentación extraída ${ }^{24}$ podemos

19 Ibidem. Folio 27.

20 La elección de una edificación hospitalaria a través de pabellones permitía una mayor insolación y ventilación transversal, además posibilitaba la especialización de cada edificio. El modelo hospitalario de pabellones que se disponen a lo largo de un corredor perpendicular fue consolidado por el inglés John Howard en el siglo XVIII. Mientras, en el siglo XIX, predomina el prototipo de edificio formado por pabellones paralelos y aislados. El sistema de pabellones será abandonado a principios del siglo XX, cuando se pasa a concentrar los edificios hospitalarios en bloques para disminuir recorridos y ahorrar energía. LÓPEZ MIHURA, Xosé Manuel, “Arquitectura hospitalaria”, Boletín Académico, no 21, Coruña, 1997, pp. 31-39

21 Libro de la Delegación de Consejo, 16 abril de 1907. Archivo Histórico Grupo Duro Felguera.

22 SAENZ DE SANTA MARÍA, José, La asistencia médica a los obreros lesionados. Sanatorio Adaro. Revista Minera y Metalúrgica, año 1946, pp.53-55.

23 VVAA., Historia-Efemérides, antes ahora y siempre. Langreo. Ayuntamiento de Langreo, Langreo, p.33 y La Nueva España, 22 de octubre de 2011.

24 Se ha podido llegar a conjeturar el aspecto que pudo llegar a tener mediante fotografías de la época y por los proyectos de reforma de los que posteriormente nos ocuparemos. 


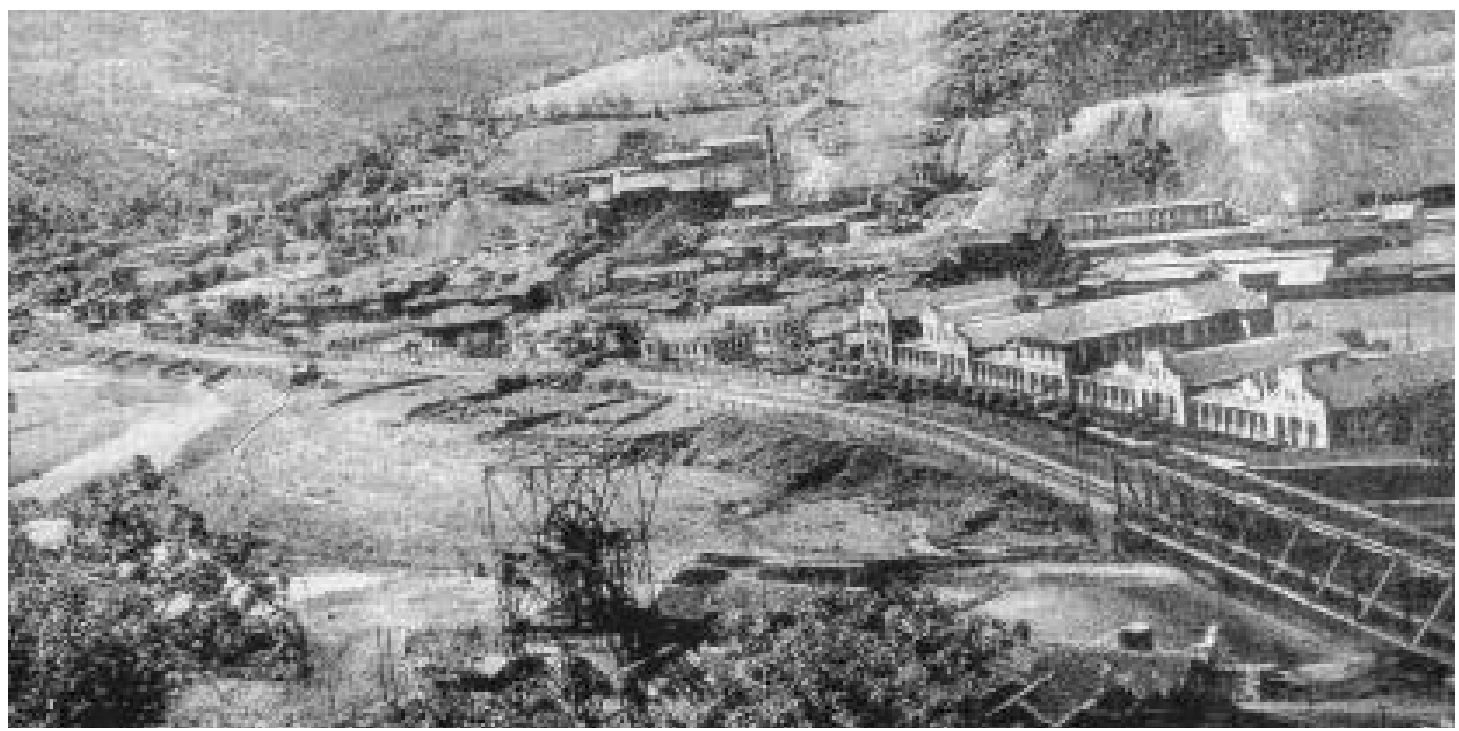

Fig. 3. Vista general del Hospital de Heridos, hacia la década de 1930. Fuente: Langreo en el pasado. Álbum fotografico (1925-1950). Vol.3

concluir que ese primer inmueble de 1914, contaba con un único pabellón con dieciséis camas. Con posterioridad, en un momento que no ha podido ser determinado, pasó a integrar dos pabellones fusionados por su espalda mediante una galería. De este modo, el pabellón primigeniamente ubicado más al norte, poseía planta rectangular y presentaba una compartimentación interior en varias estancias en torno a un pasillo central. Algunos de los espacios más relevantes en aquel momento eran la sala de operaciones y la capilla. Completaban este edificio las distintas habitaciones habilitadas como residencia de las monjas dominicas ${ }^{25}$ que se hacían cargo del cuidado de los enfermos en ese momento.

Entre los dos pabellones, se levantaba un edificio auxiliar, de reducidas dimensiones, en el que se alojaba el espacio dedicado a cocina. En último lugar, se ubicaba el restante módulo más tarde conocido como Covadonga, de magnitud pareja al primero descrito aunque con una distribución interna diversa: contaba con una amplia sala, diáfana, que albergaba veinte camas para los enfermos a través de la cual se accedía, desde un pasillo, a las estancias de rayos X y comedor.

En lo que respecta al alzado, en los momentos iniciales el edificio se desarrollaba mediante una sola altura. De otro lado, sus paños murales se articulaban mediante la apertura de manera sencilla a través de ventanales de gran verticalidad, con recercado en la parte superior. Es así como se imprimía un cierto sentido ascendente a los pabellones contrarrestado por la horizontalidad

25 Libro de Actas del Comité directivo. 26 de agosto de 1914. Archivo Histórico Grupo Duro Felguera. introducida por la galería trasera integrada por anchos vanos cuadrangulares. En las inmediaciones de este conjunto se ubicaba un edificio exento utilizado como depósito de cadáveres que lindaba al frente con el camino paralelo al río Nalón ${ }^{26}$.

De un momento ligeramente posterior encontramos el testimonio de Jove y Canella que en su Topografía Médica del Concejo de Langreo indica cómo, en 1925, este Hospital de Heridos prestaba servicio a unos nueve mil obreros. Poseía habitaciones independientes de aislamiento e infecciones determinadas, sala de asepsia y operaciones, sala de curas, grandes comedores, cuarto ropero, capilla, baño, despacho de consultas, instalaciones de radiología y amplias galerías de recreo para enfermos ${ }^{27}$.

Llegamos así al año 1929 cuando se advierte la insuficiencia de estas instalaciones por lo que se decide realizar una ampliación. Esta se materializó a través de la erección de un nuevo pabellón, el Santa Bárbara, y un ala secundaria, situados a septentrión de lo construido hasta entonces. En lo que respecta al prototipo arqui-

26 Este hospital para heridos mineros y siderúrgicos de la empresa S.M.D.F. acogería la visita del por aquel entonces ministro de Fomento, Alcalá Zamora, que en 1918 realiza una inspección a la cuenca carbonífera de Asturias. En ABC Madrid, 31 de enero de 1918.

27 Destaca además el excepcional emplazamiento con el que contaba, elevado sobre amplios jardines a orillas del río y orientado al mediodía, pasando por delante de su puerta el ferrocarril minero, que facilitaba el rápido traslado de los heridos desde el lugar del accidente al de su tratamiento. JOVE Y CANELLA, José María, Topografía médica del concejo de Langreo, Imp. de la Ciudad Lineal, Madrid, 1925, p.111. 


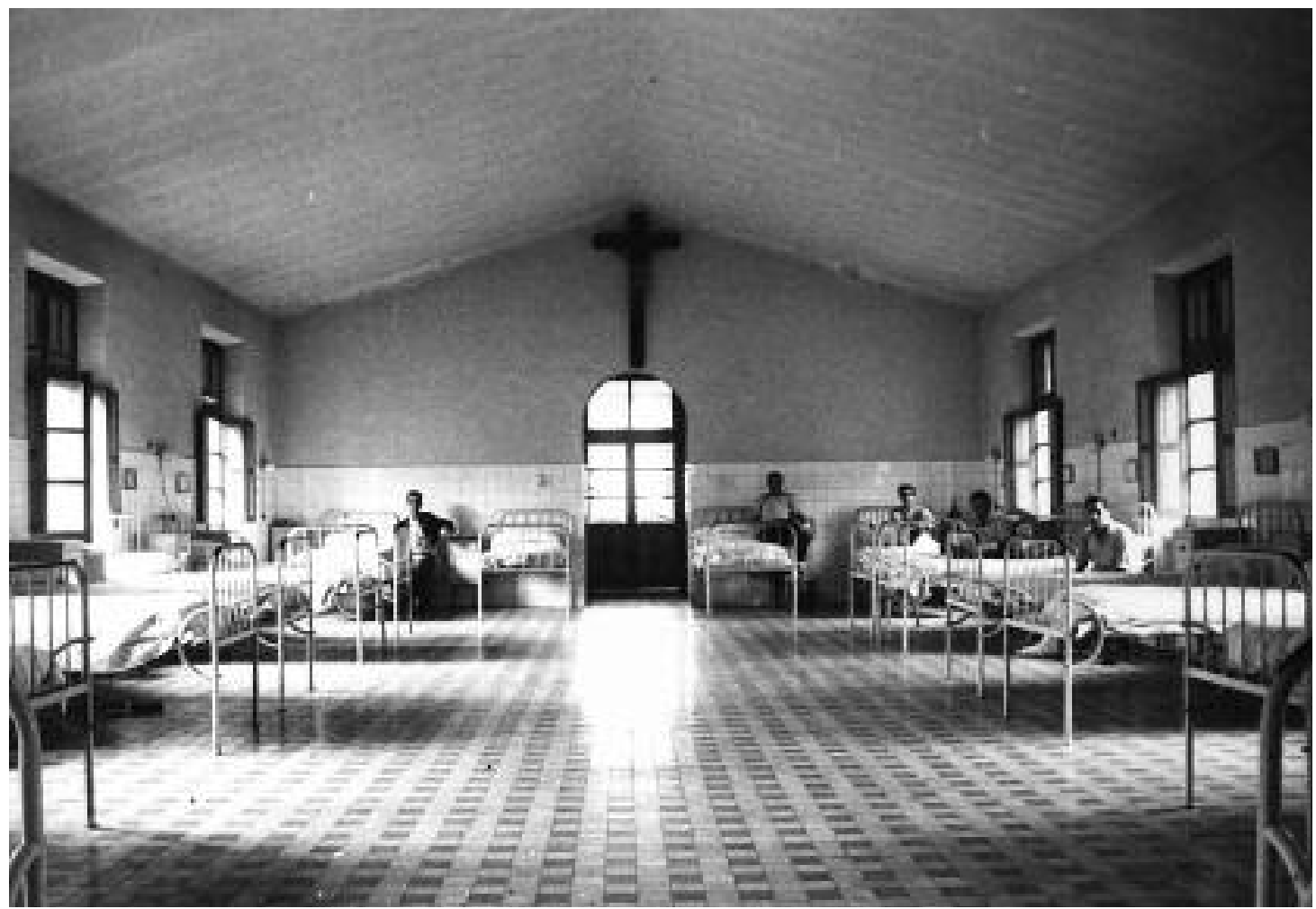

Fig. 4. Interior de una de las salas del Sanatorio Adaro en la década de 1950. Fuente: Archivo Grupo Duro Felguera

tectónico escogido, no difería sustancialmente de los levantados con anterioridad albergando nuevas veinte camas además de diversos servicios auxiliares.

Comenzaron, al propio tiempo, a tener lugar las negociaciones encaminadas a la formación de un patronato que pudiera ocuparse de la administración del hospital. Como consecuencia se produciría la ampliación del radio de acción del Hospital de Heridos ya que, el resto de empresas del concejo, no contaban con instalaciones asistenciales, debiendo trasladar a sus obreros accidentados a hospitales particulares de Gijón u Oviedo. No fue hasta agosto de ese mismo año, 1929, cuando se concretó el acuerdo de constituir un patronato ${ }^{28}$ con el respaldo de Antonio Lucio Villegas, director de la Sociedad, los estatutos datan de mayo de $1930^{29}$. Las sociedades que lo componían eran, junto la S.M.D.F., Carbones Asturianos, Carbones de La Nueva, Don Joaquín Velasco (Coto del Musel), Nespral y Compañia, Carbones de la Piquera, Minas de Escobio, Minas de Langreo y Siero, Minas de la En-

28 Libro de Actas del Comité delegado. 29 de agosto de 1929. Archivo Histórico Grupo Duro Felguera.

29 Bases y reglamento del Patronato para mineros heridos de Langreo, 1 de mayo de 1930. Archivo Histórico Grupo Duro Felguera. carnada y Sociedad anónima Felgueroso. Por su parte, la S.M.D.F. aportó el disfrute de su hospital junto a todos los materiales de los que estaba dotado, mientras, el resto de componentes participaron depositando cantidades en metálico según el número de obreros que estaban a su cargo.

La constitución del patronato trajo consigo una inyección económica, la cual se tradujo en la ampliación de las instalaciones con dos pabellones más. Al lado norte, se construyó el de San Antonio, posiblemente finalizado entre 1931 y 1932. Se organizaba mediante una planta rectangular, como los anteriores, de 344 metros cuadrados. Su distribución interior se realizaba a partir de un largo pasillo longitudinal a cuyos lados se localizaron pequeños habitáculos para habitaciones.

En un momento posterior, se llevó a cabo el pabellón de Nuestra Señora del Rosario, adosado al sur de la construcción hospitalaria ya efectuada. Se trataba del único ${ }^{30}$ que originariamente se desarrollaba en dos alturas ${ }^{31}$; el emplazamiento

30 Aunque el Pabellón central en la zona de la galería tenía dos plantas el resto de la edificación era de un solo piso.

31 Plano del Sanatorio Adaro. Ampliación de 1929 / 31 y estado de los años 50. Emplazamiento, plano, alzado. 


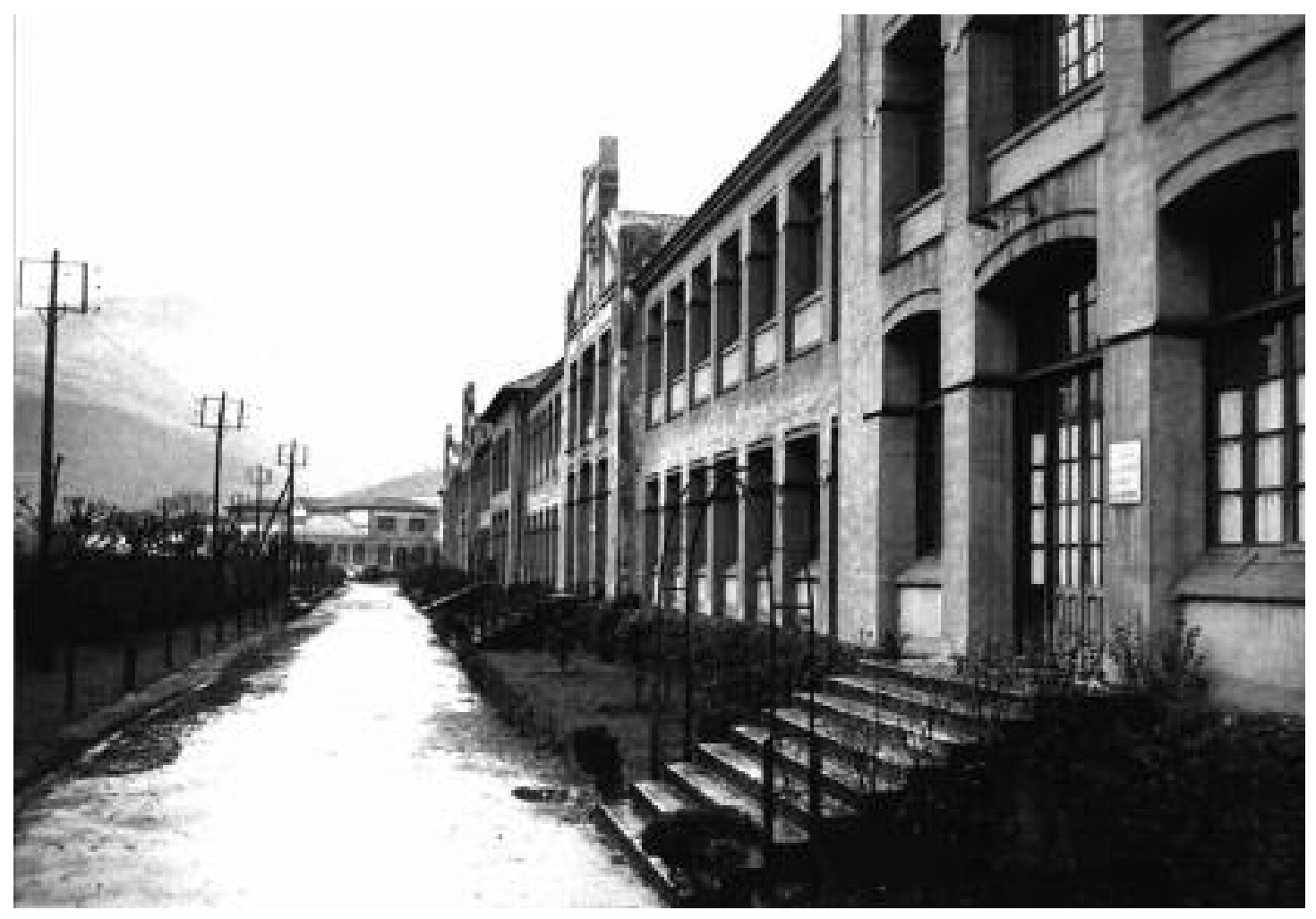

Fig. 5. Fachada posterior del Sanatorio Adaro, 1952. Fuente: Archivo Grupo Duro Felguera

de la capilla se trasladó a un ala anexa al mismo. Aunque su ejecución estaba prevista desde el momento en el que se constituye el Patronato, con toda probabilidad la Revolución de 1934 y la Guerra Civil hicieron que se retrasase su puesta en marcha definitiva.

Llegados a este punto la planta del Hospital de Heridos presentaba forma de peine, integrada por cinco pabellones exentos, de similar forma y longitud, entre los que se disponían cuatro pequeñas alas destinadas a servicios concretos. A partir de entonces se fueron acometiendo diversas ampliaciones, según necesidades, como la construcción de un nuevo quirófano, habitaciones para el capellán, el médico y el practicante, de las que apenas contamos con información documental.

Desde 1940 el Hospital de Heridos cambió su denominación por la de Sanatorio Adaro ${ }^{32}$ a iniciativa de los directivos del Patronato. Seis años después se tomó la decisión de extender su campo de acción a mayor número de obreros de la zona incluyendo a los de la Compañía Eléctrica de Langreo, la Sociedad Ibérica del Nitróge-

C809/1. Fondo de la Sociedad Metalúrgica Duro Felguera. Archivo Histórico de HUNOSA Pozo Fondón.

32 SAENZ DE SANTA MARÍA, José, La asistencia médica ...0pus cit., pp.53-55 no y a los empleados que pertenecían al Montepío de Duro Felguera y sus familias. Por aquel entonces prestaba servicios de cirugía, oftalmología, silicosis, odontología, rayos $\mathrm{X}$, masaje y laboratorio ${ }^{33}$.

El complejo hospitalario experimentó en los años sucesivos diversas ampliaciones a través de recrecidos en altura. De tal modo que este conjunto adoptó la estética iniciada con el pabellón de Nuestra Señora del Rosario, el primero en poseer dos alturas. Tal es así que las fachadas quedaron configuradas de la siguiente manera: sus frentes se distribuían en tres calles, cada una calada a través de dos vanos superpuestos, los del piso bajo rematados mediante un arco peraltado y los del superior con remate recto. Como remate se utilizaba una combinación de elementos decorativos integrados por molduras en relieve que sobrepasan el alero de la cubierta y enmarcan una serie de círculos concéntricos. Un frontón curvo se adoptaba como colofón en las dos calles laterales.

33 En 1942, siendo Ramón Moreno el Presidente de la Junta de Gobierno de la Mancomunidad inaugura un gimnasio en las instalaciones del Sanatorio Adaro para la rehabilitación de los heridos en accidentes de trabajo. En "Quince empresas asturianas sostienen el Sanatorio Adaro”, ABC (Madrid), 21 de septiembre de 1955. 
En lo que respecta al pabellón central, centro neurálgico del hospital y eje del inmueble, presentaba la peculiaridad de poseer el doble de anchura que el resto de las fachadas a través de una división en cinco calles con los mismos motivos decorativos de base geométrica referidos. Entre las obras de acondicionamiento ejecutadas en los años centrales del siglo XX, se custodia, en el Archivo Municipal del Ayuntamiento de Langreo, un proyecto ${ }^{34}$ de reforma del pabellón central de Julio Galán, fechado en abril de 1958. Estas consistieron en dotar de una nueva planta y otra de áticos a este inmueble, lo que suponía la retirada de la antigua cubierta junto con la disminución de la altura de las plantas ya existentes. Se produjo además una variación del aspecto exterior mediante un revestimiento en plaqueta de ladrillo o la inclusión de una marquesina sobre la puerta de entrada.

Hasta el día de hoy ha continuado experimentando diversas intervenciones, sobre todo en sus paramentos, pese a todo su estética no ha cambiado sustancialmente. En estos momentos es una fundación de titularidad privada sin ánimo de lucro, y cuenta con plazas concertadas con el Organismo Autónomo E.R.A. y el Servicio de Salud del Principado de Asturias para rehabilitación.

Con todo, en la actualidad, el aspecto del recinto hospitalario es el resultado de diferentes reformas experimentadas a lo largo de sus más de cien años de historia. Su configuración parte de una planta en peine, integrada por cinco pabellones unidos por una galería que discurre en su parte trasera integrándolos, uniéndolos perpendicularmente con ligeros retranqueos. En lo que se refiere a su alzado, el edificio no presenta uniformidad en todos sus pabellones ya que su desarrollo vertical aumenta en altura conforme la construcción avanza hacia el centro. De este modo, encontramos que los bloques de los extremos se levantan a partir de dos alturas, los consecutivos tienen tres pisos, mientras que el central posee cuatro plantas. Esta circunstancia ayuda a focalizar este punto como un lugar privilegiado, además de funcionar como contrapunto perpendicular que rompe con la horizontalidad del resto del conjunto. En lo que concierne a la

34 Se trataba de un proyecto de reforma en una de las plantas, la baja, para la instalación de unos nuevos quirófanos. También se llevó a cabo la elevación en altura del cuerpo central del hospital, al que añadió una nueva planta y otra de ático para el alojamiento de la comunidad religiosa. Este aumento en altura conllevaba la retirada de la antigua fachada. Proyecto de reforma del pabellón central del Sanatorio Adaro, Expediente: 5691-Caja: 1504, Archivo Municipal del Ayuntamiento de Langreo. articulación de sus paños murales, podemos ver un tratamiento claramente diferenciado entre la galería orientada hacia el río Nalón y el resto de la edificación, dirigida hacia la calle Jove y Canella. En este sentido, la galería, que funciona como fachada trasera, ofrece unos parámetros estilísticos que, aunque con notables variaciones, entroncan con la estética adoptada a finales de la década de 1940. Encontramos así los lienzos murales más interesantes del conjunto, cargados y enlucidos, sobre los que se abren amplios ventanales cuadrados de manera rítmica, rematados de manera singular. Tal es así que presentan recercado recto para los de las dos últimas alturas, en aquellos pabellones con más de dos pisos, mientras que en los vanos que funcionan como entrada trasera de cada uno de los cinco pabellones se incorpora una terminación a partir de dinteles curvados. Asimismo, bandas de colores enlucidas con una tonalidad distinta a la del resto de paramentos del edificio enmarcan las ventanas de los pisos inferiores y las separan visualmente. En este orden de cosas, uno de los grandes atractivos de este exterior es el ritmo pautadamente acompasado que otorga la incursión de sucesiones de pilastras entre vanos. La incorporación en cada una de ellas de motivos circulares en relieve funcionan como elemento decorativo que rompe con la monotonía del conjunto, junto con los frontones rectangulares de remate en cada una de las fachadas de los pabellones de los extremos. En lo que se refiere a la fachada orientada hacia la calle Jove y Canella, el tratamiento de los muros difiere sustancialmente al descrito hasta el momento. Su principal característica es la incursión de plaqueta de ladrillo en las paredes, quedando singularizada la parte reservada a los vanos mediante la utilización de franjas de diferentes colores a través del enfoscado del muro y el gresite. El único elemento que rompe con esta uniformidad compositiva exterior es la capilla, de pequeñas dimensiones, y cuyos paramentos se presentan enlucidos y pintados, con una moldura que recorre los vanos unificándolos, la entrada a la misma se practica desde el interior de las instalaciones.

Con un vocabulario arquitectónico semejante al comentado para el Sanatorio Adaro se encontraba en sus proximidades un dispensario antituberculoso ${ }^{35}$, con disposición perpendicular.

35 El edificio aparece inventariado como pabellón de la asociación de socorros mutuos en el Inventario de Patrimonio Industrial Histórico de Langreo. Equipamientos e infraestructuras, ficha n²2 C, 2002, Ayuntamiento de Langreo. 
Su morfología ha podido ser reconstruida gracias a alguna instantánea de la época puesto que la edificación ha desaparecido

Gracias a una fotografía ${ }^{36}$ de 1942 podemos observar que originariamente la edificación estaba integrada por dos pabellones independientes, uno dedicado a dispensario antituberculoso y el otro a puericultura. Ambos, iguales, se organizaban a partir de una planta cuadrangular irregular y se desarrollaban en una planta de sótano y una única altura. En su fachada, precedida por una imponente escalera, encontramos los mayores puntos de conexión con el Sanatorio Adaro. Sus fachadas se organizan a través de cinco vanos concatenados coincidiendo con el piso alto. Por lo demás el lienzo mural se animaba a través de la inclusión de molduras, recercados, impostas, además de la bicromía con la que fueron tratados. Es reseñable, asimismo, la inclusión de un frontón en la zona central de la fachada decorado a base de motivos lineales bajo el que se alojaban los letreros "Dispensario Antituberculoso" y "Puericultura".

\section{Conclusión}

A modo de conclusión, podemos establecer que la consecución de derecho de cobertura sanitaria por parte de los trabajadores no fue un hecho fortuito. Su concreción fue fruto de un lar- go proceso que tuvo como punto de partida la situación de extrema vulnerabilidad en la que, a consecuencia de la industrialización, se encontraron los trabajadores y sus familias. Como medida para atajar esta situación, y al amparo de algunos textos legales, se fueron creando sociedades de socorros mutuos de trabajadores. Así, a través de una porción del salario que les era descontada mes a mes, estos se aseguraban una asistencia médica y farmacéutica en caso de accidente o enfermedad laboral. Al mismo tiempo, la patronal observó las posibilidades domesticadoras a través de la gestión de cajas de socorros como práctica paternalista, para acallar el malestar de los obreros y sus reivindicaciones. Encontramos, en este sentido, esta circunstancia ejemplificada a través de la estrategia paternalista de la Sociedad Duro Felguera, mediante la creación de una caja de socorros mutuos en 1857 y un pequeño hospital para obreros que desembocará en la construcción por parte de la empresa del Hospital de Heridos Sanatorio Adaro, a principios del siglo XX. Enmarcado en el contexto de la Ley de Accidentes de trabajo de 1900, se trata de una construcción desarrollada a través de pabellones, la cual fue aumentando sus dimensiones conforme a las necesidades por crecimiento del número de obreros en la zona. Llegó a contar con las instalaciones médicas más avanzadas del momento y con el tiempo pasó a gestionar un patronato de varias empresas de la zona.

36 Véase VV.AA., Langreo en el pasado, álbum fotográfico 1925-1950, Langreo, 1996. 
